Palimpsesto Vol. 11, № 18 (enero-junio, 2021): 117-129

Universidad de Santiago de Chile, ISSN 0718-5898

Margarita Cantero Ramírez

Universidad de Guadalajara

margarita.cantero.ramirez@hotmail.com

\title{
Emprendimiento de microempresas familiares por migrantes de retorno como mecanismo de reintegración al mercado laboral
}

\author{
Entrepreneurship of Family Micro-businesses by Return Migrants \\ as a Mechanism for Reintegration into the Labor Market
}

\begin{abstract}
Resumen
El estudio de microempresas familiares predomina desde perspectivas económicas y de mercadotecnia, poco se retoma como mecanismo para la reintegración laboral de migrantes de retorno. Por ello el objetivo de este trabajo es describir brevemente cómo el emprendimiento de micro empresas familiares abona a la reintegración al mercado laboral de migrantes de retorno. Se realizó un estudio documental basado en una revisión y análisis de literatura de las bases de datos de Sage, Jstor y Ebsco. Entre los resultados se identificó que los distintos tipos de remesas, experiencia de la migración, condiciones del retorno, las condiciones socioeconómicas de la familia y el apoyo del gobierno por medio de políticas públicas influyen en los emprendimientos.
\end{abstract}

Palabras claves: Emprendimiento, empresas familiares, migración de retorno, reintegración laboral.

\begin{abstract}
The family microenterprises studies are dominate by the economic and marketing perspectives. However, a little is taken the microenterprises as a mechanism for the labor reintegration of return migrants. Therefore, the objective of this paper is to briefly describe how the entrepreneurship of family microbusinesses contributes to the reintegration of returning migrants into the labor market. The study explores the literature review and analysis of the Sage, Jstor, and Ebsco databases. Among the results, identified that the different types of remittances, migration experience, return conditions, the family's socioeconomic conditions, and government support through public policies influence entrepreneurship.
\end{abstract}

Keywords: Entrepreneurship, family businesses, return migration, labor reintegration. 


\section{Introducción}

En los estudios sobre empresas familiares en sus distintos tamaños, predomina una visión económica y de mercadotecnia, a partir de las cuales se resalta la relación de la presencia en los mercados con la generación de riqueza, estableciendo que cuanto más fuerte es dicha relación más exitosas son las empresas en general. La mayoría de los estudios abarcan cuestiones de competitividad, donde los datos generados son utilizados como sustento para cuestionar el papel de las microempresas familiares en las dinámicas comerciales. Pues suelen ser descritas como conflictivas, ineficaces y condenadas al fracaso al no ser competitivas frente a otros tipos de empresas (Almaraz, 2016; Escamilla, 2018).

Sin embargo, otros autores como González, Osorio y Mungaray (2018), así como Escamilla (2018) reconocen la importancia social de estas empresas al ser una fuente local de autoempleo y una herramienta para la subsistencia dado que llega a generar más empleos con lo cual impacta en el crecimiento y desarrollo de los lugares en las que están insertas a la par que contribuyen al bienestar social. Además, en este tipo de empresas se refuerzan las relaciones sociales a través de lazos no solo consanguíneos sino también legales, morales, de amistad y vecindad, así como de compadrazgo y paisanazgo que llegan a interrelacionarse.

En este sentido, un tema que ha cobrado auge en los últimos años es la relación entre la migración y el emprendimiento de empresas familiares, principalmente en su tamaño micro y pequeño donde las remesas juegan un papel central. Si bien se reconoce que el fenómeno de la migración es muy amplio, en este documento es de interés partir de la migración internacional que se ha entendido como un mecanismo parte de las estrategias familiares para tratar de solventar el gasto y las necesidades básicas de la familia al mantener comunicación constante por diversos medios tecnológicos (Canales, 2013; Lotero-Echeverri y Pérez-Rodríguez, 2019; Douglas, Atangu, Graeme, Kouaouci, Pellegrino y Taylor, 2000 Rodíguez y Cumbrado, 2018).

De tal manera que la migración internacional impacta en la forma en que se estructuran las sociedades, pues se crean espacios sociales transnacionales que aportan elementos principalmente relacionados recursos humanos y capital para el desarrollo económico y social en los lugares de destino, así como en los de origen. Asimismo, se interrelacionan las actividades sociales por medio de redes igualmente transnacionales con las que cuenta el migrante el cual en este contexto suele denominarse como transmigrante (Beck, 1997; Rodíguez y Cumbrado, 2018).

Es decir, que la noción de transmigrante ayuda a repensar la movilidad espacial de la persona y el alcance de sus redes sociales que pueden llegar a distintas latitudes donde se mantienen aquellas desarrolladas en los lugares de origen a la vez que puede establecer nuevas relaciones en el lugar de destino. A partir de esto se han fortalecido concepciones donde las fronteras nacionales no excluyen totalmente intercambios y comunicaciones que se dan entre las personas que conforman las diversas redes, sino que permiten reconstruirlas y repensarlas a partir del transnacionalismo que reconoce el mantenimiento e incluso fortalecimiento de lazos sociales más allá de estas fronteras geográficas identificados por los Estados-nación, permitiendo visibilizar el flujo de elementos económicos, sociales, políticos y culturales (Rodicio-García y Sarceda-Gorgoso, 2019; Rodríguez y Cumbrado, 2018).

En esta perspectiva en un estudio realizado en conjunto entre la Comisión Económica para América Latina y el Caribe (CEPAL) y el Fondo Internacional de Desarrollo Agrícila 
(FIDA) en 2020, señalaron que la migración se da principalmente por la búsqueda de mejores condiciones de vida, trabajo, como una estrategia familiar para enfrentar dificultades de tipo económico, así como de inseguridad aunado a motivos relacionados con la reunificación familiar. Lo cual expone a la migración como un proceso que permite conectar a diversas sociedades con la finalidad de tratar de superar limitaciones con mecanismos como el ahorro pensado en la inversión ya sea promovido por algún familiar, amigo o por el retorno del transmigrante (Croitoru, 2020; Rodríguez y Cumbrado, 2018; Guerra, 2017; Salas y Montes de Oca, 2019).

El retorno de los transmigrantes se ha identificado como un fenómeno que conlleva la reintegración a las sociedades de origen, donde surgen diversos retos donde las autoridades en ocasiones intervienen para ofrecer condiciones que faciliten ambos procesos al ser parte de los compromisos internacionales adquiridos, entre ellos lo normado en la Declaración Universal de Derechos Humanos (1948), donde se habla en su numeral 13 del derecho a regresar al país de origen.

En este sentido algunos estudios sobre migración planteaban el retorno como la finalización del proceso migratorio al considerarlo algo definitivo. Sin embargo, posteriormente se reconoció que el retorno puede ser temporal y diferente en cada migrante. Entre los temas que se han abordado de este proceso, es de interés recuperar aquellos sobre la reinserción sociocultural y laboral de los transmigrantes a sus sociedades de origen y mercado de trabajo respecto a cómo utilizan su capital económico y sociocultural en dicha reinserción (Cruz, Salas y Pico, 2018; Solís, 2018; Tovar, Victoria, Tovar, Troncoso y Pereira, 2018).

A partir de lo anterior el objetivo de este trabajo es describir brevemente cómo el emprendimiento de microempresas familiares es un mecanismo que abona a la reintegración al mercado laboral de migrantes de retorno. Para lo cual se realizó un estudio documental basado en una revisión y análisis de literatura recuperada de las bases de datos de Sage, Jstor y Ebsco, considerando documentos producidos en el periodo de 2010 a 2020 por instituciones internacionales y nacionales, así como algunos textos considerados clásicos que ayudan a comprender temas de migración como el que se plantea.

\section{Migrantes de retorno como emprendedores de microempresas familiares}

La migración de retorno alude al regreso del transmigrante a su lugar de origen, la cual suele clasificarse en forzada y voluntaria. Entre los principales motivos de retorno Solís (2018) y Guerra (2017) resaltaron el padecer alguna enfermedad o que la padezca algún familiar, contraer matrimonio, la deportación y el deseo de reunirse con la familia. Mientras que Tovar y Victoria (2013), así como Bermúdez y Zapata (2019) lo atribuyeron mayormente a las políticas restrictivas de visas que en ocasiones no permiten su renovación orillando al transmigrante a retornar, también ocurre cuando se ven arrestados y no contaban con estos documentos que acreditaran su estancia en el extranjero y son repatriados o bien el transmigrante decide retornar voluntariamente por algún cambio en sus condiciones personales, entre las cuales resalta la vejez, influencia de familiares y amigos, así como la muerte de algún familiar o el alcanzar el objetivo planteado como motivo de la migración internacional.

Además, Haase y Honerath (2016), así como Tovar y Victoria (2013) y el Consejo Nacional de Población (CONAPO, 2015) coincidieron con los autores anteriores al señalar que el retorno puede ser de distintos tipos, entre ellos voluntario del migrante establecido como 
jubilados, del migrante temporal donde se ubica a aquellos que forman parte de programas laborales o con contratos temporales, el retorno transgeneracional donde quienes regresan son los descendientes del transmigrante. Otros tipos de retorno son por migración fallida a partir de haber podido cumplir el objetivo de la migración, el forzado entre ellos por deportación, el retorno programado generalmente promovido por autoridades gubernamentales y el voluntario.

En todos estos tipos de retorno la reintegración social cobra relevancia en los procesos locales de las comunidades de origen, pues en ocasiones suelen verse como una carga tanto por los gobiernos como por los miembros de la sociedad. Aunque la integración en el mercado laboral puede verse favorecida por las capacidades, habilidades y destrezas adquiridas en su estancia en el extranjero (CONAPO, 2015; Haase y Honerath, 2016; Tovar y Victoria, 2013).

Asimismo, Tovar y Victoria (2013) y Tovar, Balanta, Ordoñez y Serna (2018), identificaron que los migrantes retornados en ocasiones optan por el autoempleo apoyados de las remesas que estuvieron enviando y ahorrando, de esta manera continúan apoyando a la familia mientras se autoemplean generalmente por medio de micro y pequeñas empresas familiares. Estos emprendimientos pueden ser por necesidad al no encontrar otra alternativa para seguir generando ingresos o bien, por oportunidad donde existe una mayor planeación de la incorporación al mercado laboral local donde se puede recurrir no solo a los recursos propios sino también a líneas de crédito de instituciones formales o de las relaciones sociales, así como a programas de emprendimiento por parte del gobierno.

La reintegración de los transmigrantes a los mercados laborales contribuye al desarrollo económico y social de sus comunidades. Para ello hacen uso de los capitales humanos, socioculturales y económicos de los que disponen a nivel personal y familiar para utilizarlos en el emprendimiento. Para la generación de estos autoempleos o emprendimientos Tovar et al. (2018), así como Tovar et al. (2018) consideraron que la experiencia en el extranjero es un elemento clave para que el migrante retornado decida emprender dado que por medio de ella puede adquirir habilidades, recursos y redes que le facilite identificar y aprovechar oportunidades laborales.

Cabe señalar que el autoempleo para autores como Croitoru (2020) representa una forma de emprendimiento que permite la búsqueda de mayor independencia laboral asumiendo distintos tipos de riesgos, entre ellos económicos, políticos y administrativos. Además, este autor aclara que no todos los migrantes retornados se convierten en emprendedores pues considera que influye el contexto en el que se dio el regreso. De tal manera que quienes regresan por voluntad propia han desarrollado mayores emprendimientos en comparación con quienes fueron deportados, siendo estos últimos quienes suelen enfrentar mayores dificultades para reintegrarse al mercado laboral principalmente por no tener una disposición para hacerlo al buscar volver a migrar.

También se han identificado las características sociodemográficas de migrantes internacionales de retorno que se desempeñan como emprendedores, entre ellas que suelen ser hombres en edades entre 40 y 49 años con formación académica básica e incluso con estudios superiores y generalmente solteros. También suelen tener una alta autoconfianza en sus habilidades y conocimientos, asimismo se identifica que pasaron al menos tres años fuera de su país de origen (Cruz et al., 2018; Croitoru, 2020; Lotero-Echeverri y Pérez-Rodríguez, 2019; Rodríguez y Cumbrado, 2018).

En cuanto a los motivos por los cuales deciden emprender una microempresa familiar se encuentran el deseo de trasladar la experiencia adquirida en el extranjero en el contexto de origen donde puedan invertir las remesas económicas e inmateriales que poseen para materializar un 
Margarita Cantero Ramírez

negocio propio. De igual manera se ha documentado este mecanismo de autoempleo como una fuente para el sustento familiar (Rodríguez y Cumbrado, 2018).

De tal manera que se dan emprendimientos en distintos sectores económicos reflejados en micronegocios familiares como el de comercio por medio de bares, restaurantes, cafeterías, peluquerías, entre otros. Mientras que, en el sector de primario, suelen centrarse en la agricultura y ganadería con la siembra y cría de animales para su comercialización, así como para el consumo humano (Cruz et al., 2018; Hack-Polay, Igwe y Madichie, 2020; Rodríguez y Cumbrado, 2018; Solís, 2018; Tovar y Victoria, 2013).

Un factor común en los distintos tipos de emprendimientos es que los migrantes desde que se encuentran en el extranjero ahorran parte de sus recursos económicos obtenidos ya que tienen una mentalidad por un lado de ahorro y por otro de inversión para generar una fuente de ingresos alterna sin recurrir a un empleo asalariado cuando regrese a su lugar de origen, donde pueda hacer uso de su capital social, cultural y financiero (Bermúdez y Zapata, 2019; Tovar y Victoria, 2013).

Bajo este contexto un emprendedor, de acuerdo con Croitoru (2020) es aquel que toma riesgos, se auto emplea o cuenta por lo menos con un empleado de tal manera que por medio de sus acciones aprovecha oportunidades en el mercado e impacta social y económicamente en su comunidad. Dicha actividad económica de acuerdo con Tovar et al. (2018) puede ubicarse en el sector formal o informal con localización fija o ambulante. Estas decisiones para Cruz et al. (2018), así como para Tovar y Victoria (2013) se relacionan con la orientación y apoyo especializado al que pueden acceder los migrantes por parte de sus redes sociales e instituciones y a recursos tanto materiales como simbólicos.

Mientras que la empresa familiar en cualquiera de sus tamaños, entre ellos el micro, se caracteriza por la participación de los miembros de la familia en sus actividades comerciales. Ello demanda integración familiar y adaptaciones para vincular el ámbito familiar con el laboral al estar estrechamente vinculados. Otro elemento que influye en el emprendimiento de este tipo de empresas por migrantes retornados es el contexto local en su dimensión social, cultural, económica y política que influyen en las decisiones, normas, creencias y valores tanto familiares como empresariales. Sin embargo, entre estos elementos sobresalen las remesas como uno de los principales recursos del migrante de retorno para el emprendimiento (Croitoru, 2020; Hack-Polay et al., 2020).

\section{Las remesas como principal apoyo en el emprendimiento de microempresas familiares}

Las remesas representan flujos monetarios que se han considerado un elemento que permite potencializar esos recursos en inversiones productivas, en particular por medio de microempresas familiares (Cruz et al., 2018; Lotero-Echeverri y Pérez-Rodríguez, 2019; Solís, 2018). Por ello resulta pertinente presentar un primer acercamiento a la remisión, tipos y usos de las remesas en el proceso de emprendimiento de microempresas familiares.

En diversos estudios se expone que las remesas influyen en el desarrollo económico y social de los lugares de origen, las cuales de acuerdo con la CEPAL y el FIDA (2020) representan un área de oportunidad al exponer una necesidad social orientada a una educación financiera que permita, una vez solventadas las necesidades básicas, realizar inversiones 
financieras con el sobrante para lo cual se requiere que sean apoyadas por políticas de desarrollo productivo. De tal manera que puedan abonar a una mayor cohesión social, la generación de empleos, ambientes de trabajo seguros y estables, así como al aumento del nivel de vida de la sociedad.

A partir de lo anterior autores como Lotero-Echeverri y Pérez-Rodríguez (2019) plantearon que la migración internacional va más allá de la dependencia entre el país destino y el de origen mediada por el transmigrante, la cual ha sido central en la perspectiva tradicional de los estudios como si se tratara de un círculo vicioso donde se da la pérdida del talento humano y mayor empobrecimiento de los lugares de origen. Pues los autores resaltan que a partir de la migración internacional surgen relaciones que permiten el codesarrollo por medio de vinculaciones entre estos migrantes y actores en las sociedades de origen que se orientan a la mejora de las condiciones de vida permitiendo un desarrollo en ambos lugares.

Este codesarrollo es posible por medio de la transferencia de remesas de tipo económico, social y cultural, el retorno voluntario, así como el emprendimiento de inversiones productivas que a su vez fortalecen redes transnacionales formadas a partir de la experiencia de ser transmigrante e influye en la reinserción familiar, cultural, social y laboral al regresar al lugar de origen y ser un actor que promueve el cambio orientado a la superación de la pobreza haciendo uso de los capitales adquiridos (Lotero-Echeverri y Pérez-Rodríguez, 2019).

En este sentido, la experiencia migratoria internacional se ha relacionado con las características sociodemográficas del transmigrante donde de acuerdo con Bermúdez y Zapata (2019) en ocasiones como parte de los flujos migratorios la presencia de la mujer, así como su grado de formación y calificación para realizar tareas específicas en el lugar de destino, suele solo enunciarse sin hacer mayores acercamientos.

Es decir, que la cuestión de género se refleja en los estudios en un predominio en el interés de la participación laboral y en la migración internacional del trabajo masculino donde pocos dan una centralidad a lo femenino como parte de la reproducción social, analizando las actividades desempeñadas por mujeres que se dan en ámbitos privados como domésticos, así como en el sector informal a lo cual se atribuye esta falta de acercamientos que den cuenta de estas actividades que si se retoman en estudios feministas y de género más allá de visiones patriarcales que reproducen estereotipos (Guerra, 2017; Salas y Montes de Oca, 2019).

Por otro lado, en Latinoamérica los trabajos de autores como Solís (2018), la CEPAL y FIDA (2020) exponen la inseguridad e inestabilidad laboral que en ocasiones no alude solo a la falta de empleo sino a las condiciones y remuneraciones que ofrecen. Estas condiciones laborales se han denominado como precariedad en la cual se distingues cuatro dimensiones, la primera de ella relacionada con la temporalidad del empleo al no haber un contrato que regule el tiempo de la relación laboral; la segunda dimensión es de vulnerabilidad donde las condiciones llegan a ser insalubres o de riesgo físico y en general para la salud del trabajador; la tercera dimensión versa sobre insuficiencia salarial para dar cuenta de salarios que no permiten satisfacer las necesidades básicas de los hogares; finalmente, la cuarta dimensión trata la desprotección laboral en el sentido de falta o inexistencia de prestaciones laborales estipuladas por la ley laboral.

Ante esta precariedad en los mercados de trabajo, las remesas que envían los migrantes les permite solventar las necesidades de sus familias en los lugares de origen y en ocasiones incursionar en el emprendimiento de microempresas familiares evitando hasta cierto punto las limitaciones de acudir a financiamientos de instituciones de la banca comercial como la necesidad de garantías y el comprobar su capacidad de pago (Rodríguez y Cumbrado, 2018; Solís, 2018). 
Margarita Cantero Ramírez

Cabe señalar que las remesas no solo pueden ser de tipo económico sino también inmateriales representadas en transferencias o remesas socioculturales reflejadas en las prácticas, comportamientos, ideas y redes sociales de los transmigrantes, así como en sus experiencias, habilidades y conocimientos que les permiten desarrollar actividades específicas que permitan también invertir en capital de trabajo o expansión de las microempresas familiares que impactan y contribuyen en el desarrollo de la economía local (Cruz et al., 2018; Rodríguez y Cumbrado, 2018; Solís, 2018).

Además, algunos de los elementos que se suelen relacionar positivamente con el emprendimiento de migrantes retornados son los ahorros que llegan a tener de manera individual $\mathrm{y}$ en el contexto familiar, las redes sociales de las que dispone, las remesas socioculturales, el género dado que diversos estudios identifican que el hombre tiene mayores probabilidades de emprender e invertir sus recursos en un negocio cuando retorna a su lugar de origen después de haber migrado al extranjero, así como la restitución en la estructura y dinámica familiar dado que afecta la toma de decisiones sobre el emprendimiento, dado que la reinserción también es familiar (Croitoru, 2020; Hack-Polay et al., 2020; Tovar et al., 2018; Tovar et al., 2018).

\section{Migración de retorno y emprendimiento de microempresas familiares en algunas partes de México}

Para ilustrar los elementos teóricos descritos a continuación se presentan algunos datos empíricos que dan cuenta del emprendimiento de microempresas familiares por migrantes de retorno como mecanismo de reintegración al mercado laboral en México, ello partiendo del reconocimiento y particularidades de los flujos migratorios a nivel internacional y el retorno a este país, así como algunas condiciones y necesidades propias de cada migrante retornado. En los flujos de migración internacional de México durante 2019, de acuerdo con Serrano y López (2020) este país se posicionó como el segundo a nivel mundial respecto a la participación de población migrante (ver Tabla 1).

También en los datos presentados por Serrano y López (2020), igualmente sobresale que la mayoría (97.4\%) de los migrantes internacionales mexicanos en el año 2019 prefirieron como lugar de destino a los Estados Unidos, mientras que pocos de ellos (2.60\%) opta por emigrar a distintos países, entre ellos en segundo lugar se ubica Canadá (0.73\%). Sin embargo, México a pesar de ser de los países a nivel mundial del que salen más migrantes, no figura entre los diez países que las personas deciden emigrar o que consideran como lugar de destino (ver Tabla 2). 
Tabla 1.

Datos descriptivos de los principales países de origen de población migrante internacional en 2019

\begin{tabular}{|c|c|c|c|c|c|c|c|}
\hline \multirow[t]{3}{*}{ Lugar } & \multirow{3}{*}{$\begin{array}{l}\text { País de } \\
\text { origen }\end{array}$} & \multicolumn{4}{|c|}{ Cantidad de migrantes internacionales } & \multirow{2}{*}{\multicolumn{2}{|c|}{ Participación mundial }} \\
\hline & & \multicolumn{2}{|c|}{ Mujeres } & \multicolumn{2}{|c|}{ Hombres } & & \\
\hline & & $\mathrm{f}$ & $\%$ & $\mathrm{f}$ & $\%$ & $\mathrm{f}$ & $\%$ \\
\hline 1 & India & 6076293 & 34.7 & 11434638 & 65.3 & 17510931 & 6.4 \\
\hline 2 & México & 5520611 & 46.8 & 6275567 & 53.2 & 11796178 & 4.3 \\
\hline 3 & China & 5763235 & 53.7 & 4969046 & 46.3 & 10732281 & 4 \\
\hline 4 & Rusia & 5927819 & 56.5 & 4563896 & 43.5 & 10491715 & 3.9 \\
\hline 5 & Siria & 3388906 & 41.2 & 4836593 & 58.8 & 8225499 & 3 \\
\hline 6 & Bangladesh & 2626941 & 33.4 & 5218211 & 66.6 & 7835152 & 2.9 \\
\hline 7 & Pakistán & 2174634 & 34.5 & 4128652 & 65.5 & 6303286 & 2.3 \\
\hline 8 & Ucrania & 3068555 & 52 & 2832512 & 48 & 5901067 & 2.2 \\
\hline 9 & Filipinas & 2882253 & 53.6 & 2495084 & 46.4 & 5377337 & 2 \\
\hline 10 & Afganistán & 2391393 & 46.7 & 2729363 & 53.3 & 5120756 & 1.9 \\
\hline
\end{tabular}

Nota: Elaboración propia a partir de datos del Anuario de migración y remesas México 2020.

\section{Tabla 2.}

Datos descriptivos de los principales países de destino de población migrante internacional en 2019

\begin{tabular}{|c|c|c|c|c|c|c|c|}
\hline \multirow[t]{3}{*}{ Lugar } & \multirow[t]{3}{*}{ País destino } & \multicolumn{4}{|c|}{ Cantidad de migrantes internacionales } & \multirow{2}{*}{\multicolumn{2}{|c|}{ Participación mundial }} \\
\hline & & \multicolumn{2}{|c|}{ Mujeres } & \multicolumn{2}{|c|}{ Hombres } & & \\
\hline & & $\mathrm{f}$ & $\%$ & $\mathrm{f}$ & $\%$ & $\mathrm{f}$ & $\%$ \\
\hline 1 & $\begin{array}{l}\text { Estados } \\
\text { Unidos }\end{array}$ & 26191814 & 51.7 & 24469335 & 48.3 & 50661149 & 18.6 \\
\hline 2 & Alemania & 6250901 & 47.6 & 6881245 & 52.4 & 13132146 & 4.8 \\
\hline 3 & Arabia Saudita & 4120414 & 31.4 & 9001924 & 68.6 & 13122338 & 4.8 \\
\hline 4 & Rusia & 835045 & 50.9 & 805514 & 49.1 & 1640559 & 4.3 \\
\hline 5 & Reino Unido & 4967097 & 52 & 4585013 & 48 & 9552110 & 3.5 \\
\hline 6 & $\begin{array}{l}\text { Emiratos } \\
\text { Árabes Unidos }\end{array}$ & 2258448 & 26.3 & 6294459 & 73.3 & 8587256 & 3.2 \\
\hline 7 & Francia & 4317465 & 51.8 & 4017410 & 48.2 & 8334875 & 3.1 \\
\hline 8 & Canadá & 4171384 & 52.4 & 3789273 & 47.6 & 7960657 & 2.9 \\
\hline 9 & Australia & 3804832 & 50.4 & 3744438 & 49.6 & 7549270 & 2.8 \\
\hline 10 & Italia & 3362715 & 53.6 & 2911007 & 46.4 & 6273722 & 2.3 \\
\hline
\end{tabular}

Nota: Elaboración propia a partir de datos del Anuario de migración y remesas México 2020. 
En México, se han realizado algunas investigaciones que dan cuenta de las realidades en distintos puntos regionales. Entre ellos García (2018) describió por medio de entrevistas semiestructuradas el caso de migrantes de Yucatán que emigraron a Estados Unidos para aprender estrategias y técnicas que les ayudarán a mejorar sus procesos de producción y venta de café, así como para obtener ideas de qué servicios y productos derivados podían ofrecer en el mercado de su lugar de origen.

Esto da cuenta de las remesas socioculturales que adquirieron e implementaron a su retorno con apoyo de micro financiamiento por parte del Gobierno local y la cooperación con otros caficultores. De tal manera que ello les permitió fortalecer los emprendimientos propios y de su sociedad para mejorar a la par sus actividades económicas con el bienestar y desarrollo. Ello expone que en este caso particular del Golfo de México aspectos latentes como la confianza, cooperación y satisfacción influyen en la toma de decisiones relacionadas con aspectos de emprendimiento, gestión e innovación (García, 2018).

De igual manera, Solís (2018) estudió la reinserción laboral de migrantes retornados a Yucatán exponiendo que más allá de factores individuales y familiares, resulta fundamental el apoyo de los gobiernos por medio de políticas públicas que atiendan las necesidades de estas personas que regresan. A partir de las cuales también se proteja de manera general los derechos laborales de todos los trabajadores apostando a una reducción de la precariedad laboral y potencializando emprendimientos al establecer relaciones de confianza y cercanas que brinde las condiciones y recursos necesarios para que sean exitosos.

Por otra parte, García, Peláez y Fuentes (2015) también estudiaron a los migrantes retornados de Estados Unidos a Guanajuato que es uno de los estados mexicanos que recibe mayor volumen de remesas per cápita, en particular se enfocaron en el uso que se les da a las remesas como fuente de financiamiento de negocios locales. Para ello partieron de datos de la Encuesta Nacional de Ingresos y Gastos de los Hogares (ENIGH, 2010) y del enfoque teórico desarrollista-funcionalista que plantea a la migración internacional como uno de los resultados sociales ante la falta de desarrollo que al regresar a los lugares de origen fomentan la innovación y el cambio. Lo cual se relaciona con el uso que dan los hogares a las remesas que reciben, el que se utilicen no solo para satisfacer sus necesidades básicas, sino que se contemple su inversión en actividades productivas que a la vez llegan a incrementar las fuentes de empleo.

Un aspecto muy señalado en diversos estudios es que la migración representa una estrategia familiar para enfrentar riesgos, dificultades y diversificar las fuentes de ingreso de la familia. Entre ellas una estrategia derivada de la migración es destinar parte de las remesas a emprender proyectos productivos como microempresas familiares, lo cual estimaron a partir de modelos estadísticos como el logit que calcula la intensidad y el sentido de las relaciones entre variables como la capacidad explicativa de las remesas en inversión de microempresas familiares, al tiempo que brinda análisis descriptivo de las mismas (García et al., 2015).

Mientras que Cruz et al. (2018) describieron las características sociodemográficas de migrantes de retorno en el Estado de México al entrevistarlos y emplear un modelo probit por medio del cual identificaron entre los factores que promueven el emprendimiento a las características en que se da el retorno, la experiencia migratoria, el ahorro de las remesas, la situación económica familiar y social a partir de las cuales se da escasez de empleo, salarios bajos y en general la precarización laboral. Por lo cual para el migrante retornado el emprendimiento como mecanismo de autoempleo como pequeño empresario le resulta más atractivo que la búsqueda de un empleo asalariado para su reintegración laboral. 
Lo anterior se evidencia de mejor manera en el estudio de Salas y Montes de Oca (2019) donde identifican de manera puntual el uso de remesas en México, señalando que se destinan a adquirir bienes y servicios relacionados con comida y vestido (78.2\%), salud (39.6\%), vivienda (29.5\%), educación $(9.9 \%$ ) y en menor medida que no se especifica, se destinan para el pago de deudas y emprender negocios como un mecanismo de autoempleo.

\section{Conclusiones}

A partir del análisis documental realizado, se puede concluir que el emprendimiento de micro empresas familiares es un mecanismo que abona a la reintegración al mercado laboral de migrantes de retorno, que sus acercamientos han sido variados e incluso desde la multidisciplina donde se empelan enfoques cualitativos y cuantitativos con la finalidad de abonar a la comprensión de este fenómeno social, sobre el cual la mayoría de los autores identifican una débil vinculación de los Gobiernos exponiendo la falta de políticas públicas que faciliten y promuevan no solo el retorno a los lugares de origen sino también una reintegración en distintos ámbitos como el laboral, familiar, cultural, político y social.

Un punto en común es el reconocimiento de la carencia de conocimiento empresarial que suelen tener los migrantes retornados y que las remesas de las que disponen pueden generar emprendimientos de microempresas familiares. Aunque en cantidad son pocos los migrantes con esta mentalidad y objetivo pues en su mayoría tienen una cultura de consumo que se relaciona con su situación socio económica que no les permite pensar en la inversión a futuro, sino que centran su atención en atender las necesidades básicas del día a día.

De tal manera que el concepto teórico de codesarrollo resulta pertinente en esta visión de cooperación, confianza y redes como base del emprendimiento y reintegración de los migrantes, quienes aportan al desarrollo de sus comunidades no solo capital económico sino también, cultural, humano y social. Siendo un agente transmisor de conocimientos, competencias y habilidades en favor del bienestar y mejora de la calidad de vida de su sociedad.

Ante ello se identificó la falta de estudios regionales centrados en territorios específicos que permitan dar cuenta de cómo se representa en su cotidianidad estos fenómenos de migración, retorno, emprendimiento y reintegración. Para lo cual sería necesario aproximaciones longitudinales que permitan dar seguimiento y documentar la evolución de estos fenómenos, las condiciones en que se dan, sus repercusiones, procesos, experiencias y demás aspectos involucrados.

Lo anterior representaría una fuente de información que permita el rediseño de políticas públicas que abonen a la reducción de brechas sobre cuestión de género, conciliación de los ámbitos familiar y laboral, discriminación, precariedad laboral, entre otras que identifique y atienda desafíos propios de cada una y en conjunto de acuerdo a las regiones y localidades de estudio, así como a partir de considerar la historia detrás de cada una de esas experiencias y la historia de la propia comunidad donde se dan los retornos.

De igual manera ello contribuirá a la protección y garantía del derecho de toda persona a regresar al país de origen, donde también se debe velar por la reintegración no solo por el retorno. Otro aspecto que no se identificó en los textos analizados son las afectaciones en la migración internacional, los retornos y dicha reintegración con contextos de mayor incertidumbre y 
emergencia tanto nacional como internacional. Por ejemplo, en la actual contingencia sanitaria que ha impactado todos los ámbitos sociales.

En este escenario han surgido programas gubernamentales de crédito a las micro, pequeñas y medianas empresas (Mipymes) en general sin distinguir si son familiares o no con la finalidad de apoyarlas ante este periodo extraordinario de cambios donde además los flujos migratorios internacionales oficialmente se han interrumpido, pero ello no significa que no se sigan dando por otros canales no regulados, es decir por medio de migraciones consideradas ilícitas.

Aunque este otro tipo de migración no se relaciona tan directamente con el emprendimiento, al estar más ligado a la obtención de recursos que permitan la sobrevivencia individual y familiar igualmente impacta en los mercados laborales al recurrir a mecanismos informales como la venta de algún bien o producto no regulado bajo las normas y estándares de instituciones gubernamentales.

Es decir, que la integración al mercado laboral de los migrantes internacionales ha sido mayormente estudiada en aquellos que retornan de manera voluntaria, al considerarse los más estables y con mayores posibilidades de realizar actividades productivas como el emprendimiento de Mipymes, entre ellas las microempresas familiares. Ello representa un área de oportunidad para realizar acercamientos a los otros tipos de retornos y el cómo se da la reintegración no solo laboral sino también familiar, cultural, política y social.

\section{Bibliografía}

Almaraz A. (2016). La empresa familiar y las familias empresariales en México: una propuesta teórica. En A. Almaraz y L. A. Ramírez (Eds.), Familias empresariales en México Sucesión generacional y continuidad en el siglo xx (pp. 47-84). México: El Colegio de la Frontera Norte.

Beck, U. (1997). ¿Qué significa la globalización? Dimensiones, controversias y definiciones. En Autor (Ed.), ¿Qué es la globalización? Falacias del globalismo, respuestas a la globalización (pp. 37-98). México: Booket.

Bermúdez, R. E. y Zapata, L. F. (2019). Trayectorias laborales de migrantes calificados retornados a la ciudad de Cali, Colombia. Revista Migraciones, 46, 35.61. doi: mig.i46y2019.002

Canales, A. (2013). La migración en la reproducción de la sociedad global. Migración y Desarrollo, 12(21), 9-41. Recuperado de http://www.scielo.org.mx/pdf/myd/v11n21/v11n21a2.pdf

Comisión Económica para América Latina y el Caribe [CEPAL] y Fondo Internacional de Desarrollo Agrícola [FIDA]. (2020). Estrategias para la inversión de remesas familiares en cadenas de valor. Recuperado de https://www.cepal.org/sites/default/files/a2020-0722-ude-pb-estrategias-inversion-rem-fam-cv-guat-esp.pdf

Consejo Nacional de Población [CONAPO]. (2015). El retorno en el nuevo escenario de la migración entre México y Estados Unidos. Recuperado de 
Margarita Cantero Ramírez

https://www.gob.mx/cms/uploads/attachment/file/39174/ElRetornoEnelNuevoEscenario deMigracion.pdf

Croitoru, A. (2020). Great expectations: A regional study of entrepreneurship among romanian return migrants. SAGE Open, 10(2), 1-18. doi: 10.1177/2158244020921149

Cruz, M., Salas, R. y Pico, B. (2018). El emprendimiento de los migrantes retornados, el papel de las características de los migrantes y las particularidades de la experiencia migratoria. El caso del Estado de México. Revista de Economía, 36(92), 46-93. Recuperado de http://www.scielo.org.mx/pdf/remy/v36n92/2395-8715-remy-36-9246.pdf

Declaración Universal de Derechos Humanos. Asamblea General de las Naciones Unidas, París, Francia, 10 de diciembre de 1948. Recuperado de https://www.ohchr.org/EN/UDHR/Documents/UDHR_Translations/spn.pdf

Douglas, S. M., Arango, J., Graeme, H., Kouaouci, A., Pellegrino, A. y Taylor, E. (2000). Teorías sobre la migración internacional. Una reseña y una evaluación. Revista Trabajo, 2(3), 5-49. Recuperado de http://www2.izt.uam.mx/sotraem/Documentos/Trabajoa2n32000.pdf

Escamilla, G. (2018). Identificación de los problemas que enfrentan las microempresas familiares para su subsistencia en Ciudad Madero, Tamaulipas (Tesis de maestría). Recuperada de http://200.188.131.162:8080/jspui/bitstream/123456789/311/1/IDENTIFICACI\%c3\%93 N\%20DE\%20LOS\%20PROBLEMAS\%20QUE\%20ENFRENTAN\%20LAS\%20MICR OEMPRESAS \%20FAMILIARES\%20PARA \%20SU\%20SUBSISTENCIA $\% 20$ EN\%20 CIUDAD\%20MADERO\%2c\%20TAMAULIPAS.pdf

García, C. (2018). Emprendimiento caficultor en migrantes de la región huasteca del centro de México. Revista Equidad y Desarrollo, 30, 119-147. doi: 10.19052/ed.4324

García, J., Peláez, O. y Fuentes, N. A. (2015). La tradición migratoria como factor explicativo del uso de remesas en la financiación de negocios en Guanajuato. Revista Migraciones Internacionales, 8(2), 165-193. Recuperado de http://www.scielo.org.mx/pdf/migra/v8n2/v8n2a6.pdf

González, J., Osorio, G. y Mungaray, A. (2018). La microempresa mexicana, un asunto de necesidad y no de oportunidad: el caso de Colima. Análisis Económico, 33(84), 123 142. doi: 10.24275/uam/azc/dcsh/ae/2018v33n84/Gonzalez

Guerra, M. J. (2017). Inseguridad humana, migración y supervivencia. Género y derechos humanos. Astrolabio: Revista Internacional de Filosofía, 17, 190-206. Recuperado de https://www.raco.cat/index.php/Astrolabio/article/view/318863

Haase, M. y Honerath, P. (2016). What do return and reintegration mean for the countries involved? Recuperado de https://www.jstor.org/stable/resrep18952.5

Hack-Polay, D., Igwe, P. U. y Madichie, N. O. (2020). The role of institutional and family embeddedness in the failure of Sub-Saharan African migrant family businesses. The International Journal of Entrepreneurship and Innovation, 21(4), 237-249. doi: $10.1177 / 1465750320909732$

Lotero-Echeverri, G. y Pérez-Rodríguez, M. A. (2019). Migraciones en la sociedad contemporánea: Correlación entre migración y desarrollo. Retos, 9(17), 145-159. doi: 10.17163/ret.n17.2019.09 
Rodicio-García, M. L. y Sarceda-Gorgoso, M. C. (2019). Inserción sociolaboral de mujeres emigrantes retornadas: Desde Venezuela a España. Revista de Ciencias Sociales, 25(4), 11-21. Recuperado de https://dialnet.unirioja.es/servlet/articulo?codigo=7201995

Rodríguez, M. O. y Cumbrado, M. A. (2018). Migración, transnacionalismo y emprendimientos privados en Cuba. Estudio de casos en el centro histórico de La Habana. Novedades en Población, 28, 181-198. Recuperado de http://scielo.sld.cu/pdf/rnp/v14n28/1817-4078rnp-14-28-181.pdf

Salas, R. y Montes de Oca, A. (2019). Migración internacional e inversión de remesas en localidades del Estado de México. Recuperado de http://ri.uaemex.mx/handle/20.500.11799/105313

Serrano, C. y López, R. (2020). Anuario de migración y remesas México 2020. Recuperado de https://www.bbva.com/wpcontent/uploads/2020/10/Anuario_Migracion_y_Remesas_2020.pdf

Solis, M. (2018). Aproximaciones al análisis de la precariedad laboral de la migración de retorno. Un estudio comparativo entre migrantes yucatecos. Revista Norteamérica, 13(1), 7-32. doi: 10.20999/nam.2018.a003

Tovar, L. M., Balanta, S., Ordoñez, J. A. y Serna, W. (2018). Factores asociados al emprendimiento por oportunidad de colombianos retornados del exterior. Revista Migraciones, 45, 119-142. doi: mig.i45.y2018.005

Tovar, L. M., Victoria, M. T. (2013). Migración internacional de retorno y emprendimiento: revisión de la literatura. Revista de Economía Institucional, 15(29), 41-65. Recuperado de https://www.redalyc.org/articulo.oa?id=41929178004

Tovar, L. M., Victoria, M. T., Tovar, J. R., Troncoso, G. y Pereira, F. (2018). Factores asociados a la probabilidad de emprendimiento en migrantes colombianos que retornan a Colombia. Revista Migraciones, 34, 169-192. Recuperado de http://www.scielo.org.mx/pdf/migra/v9n3/1665-8906-migra-9-03-00169.pdf 